\title{
Effect of Shot Peening on Microstructural Evolution of 500-7 Ductile Cast Iron
}

\author{
Yubing Zhang, Keesam Shin* \\ School of Advanced Materials and Engineering, Changwon National University, Changwon 51140, Korea
}

*Correspondence to:

Shin K,

(iD) http://orcid.org/0000-0002-9507-2087

Tel: +82-55-213-3696

Fax: +82-55-261-7017

E-mail: keesamgg@gmail.com

Received July 19, 2018

Revised August 27, 2018

Accepted August 28, 2018
Ductile cast iron is widely used for many automotive components due to its high wear resistance and fatigue resistance in addition to the low cost of fabrication. The improvement of wear resistance and fatigue properties is key to the life time extension and performance increase of the automobile parts. Surface nanocrystallization is a very efficient way of improving the performance of materials including the wear- and fatigue-resistance. Shot peening treatment, as one of the popular and economic surface modification methods, has been widely applied to various materials. In this study, ductile cast iron specimens were ultrasonic shot peening (USP) treated for 5 to $30 \mathrm{~min}$ using different ball size. The microstructures were then microscopically analyzed for determination of the microstructural evolution. After the USP treatment, the hardness of pearlite and ferrite increased, in which ball size is more effective than treatment time. With USP treatment, the graphite nodule count near the surface was decreased with grain refinement. The lager balls resulted in an increased deformation, whereas the smaller balls induced more homogenously refined grains in the deformation layer. In addition, formation of nanoparticles was formed in the surface layer upon USP.

Key Words: Ductile cast iron, Shot peening, Grain refinement, Graphite, Pearlite

\section{INTRODUCTION}

Ductile cast iron is a high-strength material developed in the 1950s. Ductile cast iron is a group of irons that exhibit high strength, flexibility, durability, and elasticity because of its unique microstructure (Radzikowska, 2004). Containing over $3 \%$ carbon, ductile cast iron is ductile like steel far exceeding the ductility of the standard cast irons. Usage of the ductile cast iron has drastically increased and it's second only to gray cast iron (William, 1992). In most cases, "iron-based steel" refers to ductile cast iron.

Shot peening is one of the most effective and economic methods of increasing the fatigue life of the machine parts. In shot peening, spherical media called shots are driven in high-speed to bombard onto the surface of the part, inducing plastic deformation and reinforcing the surface layer (Marsh, 1993). The compressive stress induced by the shot peening on the surface layer offsets the tensile stress under loading, thereby retarding the crack initiation and propagation. Shot peeing also enhance the resistance to stress corrosion cracking by breaking precipitates and segregation into more uniform morphology (Watanabe et al., 2002). There are various shot peening types classified by the impact method/equipment (Ganapathy et al., 2015; Kumar et al., 2013; Shukla et al., 2016).

Ultrasonic shot peening (USP) method is similar to the traditional shot peeing in that it uses hard balls striking on a coldworking surface of machine parts, but differs in the way the kinetic energy is provided to the shot. The energy to the balls are transferred via sonotrode (vibrating base plate) in the ultrasonic frequency range $(\sim 20 \mathrm{kHz})$. Although USP has been successfully applied to surface modification for various steels such as SS316L, S304H, etc. (Fang et al., 2014; Nam et al., 2018), studies on the effect of shot peening on the ductile cast

@ (T) This is an open-access article distributed under the terms of the Creative Commons Attribution Non-Commercial License (http://creativecommons.org/licenses/by-nc/4.0) which permits unrestricted noncommercial use, distribution, and reproduction in any medium, provided the original work is properly cited.

Copyrights @ 2018 by Korean Society of Microscopy 
irons are rare. Modification of the morphology of the constituent phases such as ferrite, cementite and pearlite as well as grain size, precipitates and other microstructural elements can lead to a drastic increase of the life time of the components and thus the application of the economic shot peening technology to the ductile cast iron.

In this study, the effect of ball size and duration of shot peening on the evolution/modification of microstructure such as grain, carbide, graphite and constituting phase of ferrite and cementite in the surface layer and on the Vickers hardness in 500-7 ductile cast have been investigated.

\section{MATERIALS AND METHODS}

In this study, 500-7 ductile cast iron often used for automotive parts fabricated by Hyundai WIA has been shot peened and the microstructural evolution has been investigated (the chemical composition and mechanical property is listed in Table 1). The ductile cast iron plates of $110 \times 30 \times 5 \mathrm{~mm}^{3}$ were polished with SiC sandpaper (finished with grit \#2000) before the USP treatment. The set-up of the USP treatment has been reported elsewhere (Yu et al., 2009). Table 2 shows fabrication parameters of the USP.

For scanning electron microscopy (SEM) observations, the cross-sectional specimens were polished and etched for about $10 \mathrm{~s}$ in a solution of $10 \%$ Nital. The polishing of the crosssectional specimens for EBSD observation was finished with diamond paste down to $1 \mu \mathrm{m}$, and then in colloidal silica for 1 $\mathrm{h}$ for removal of the damaged surface during the mechanical polishing. For EBSD analysis, a TSL-OIM system in a MIRA II LMH FE-SEM has been used with a beam size of $\sim 200 \mathrm{~nm}$. TEM measurement was carried out on a Philips CM200 FEG. The plan-view TEM thin foils of specific depths (depth here means the distance down into the bulk from the shot peened surface) were prepared by cutting, mechanical polishing down to $\sim 70 \mu \mathrm{m}$ in thickness, then double-jet electropolishing at $15^{\circ} \mathrm{C}$ (Struers TenuPol-5) in a solution of $10 \%$ perchloric acid and $90 \%$ acetic acid, with additional ion milling at $4 \mathrm{keV}$ with small degree $2^{\circ}$ to $6^{\circ}$ when necessary.

For the preparation of the TEM specimens at the specific depth, one side of the $3 \mathrm{~mm}$ disc was slightly electropolished just enough to form a shiny electropolished surface and the other side only was electropolished by blocking the electropolished side with transparent film until the perforation of the 3 $\mathrm{mm}$.

\section{RESULTS AND DISCUSSION}

\section{Vickers Microhardness}

The SEM analysis of the unpinned specimen indicated that the 500-7 ductile cast iron consists of two phases, ferrite matrix, and lamella cementite forming pearlite with surrounding ferrite. The Vickers hardness of the two phases in the cross section was measured by every $20 \mu \mathrm{m}$ from USP treated sur-

Table 1. Original specimen composition and mechanical property

\begin{tabular}{|c|c|c|c|c|c|c|c|c|c|c|}
\hline \multirow{2}{*}{ ISO } & \multicolumn{7}{|c|}{ Composition (wt. \%) } & \multicolumn{3}{|c|}{ Mechanical property } \\
\hline & $\mathrm{C}$ & $\mathrm{Si}$ & $\mathrm{Mn}$ & $\mathrm{P}$ & $\mathrm{S}$ & $\mathrm{Ni}$ & Bal. & $\mathrm{R}(\mathrm{MPa})$ & $\varepsilon(\%)$ & Hardness (HV) \\
\hline $1083500-7$ & $\sim 3.75$ & $\sim 2.25$ & $\sim 0.45$ & 0.06 & $<0.06$ & $<0.02$ & $\mathrm{Fe}$ & 500 & 7 & $\sim 200$ \\
\hline
\end{tabular}

Table 2. Ultrasonic shot peening (USP) treatment parameters (amplitude, $70 \mu \mathrm{m}$; frequency, $20 \mathrm{kHz}$ )

\begin{tabular}{lc}
\hline \multicolumn{1}{c}{ Specimen } & Treatment time (min) \\
\hline Ball size: $1.0 \mathrm{~mm}$ & 0 \\
$500-7$ & 5 \\
USP-1.0-5 & 10 \\
USP-1.0-10 & 15 \\
USP-1.0-15 & 20 \\
USP-1.0-20 & 25 \\
USP-1.0-25 & 30 \\
USP-1.0-30 & \\
Ball size: $1.5 \mathrm{~mm}$ & 5 \\
USP-1.5-5 & 10 \\
USP-1.5-10 & 15 \\
USP-1.5-15 & 20 \\
USP-1.5-20 & 25 \\
USP-1.5-25 & 30 \\
USP-1.5-30 & \\
\hline
\end{tabular}

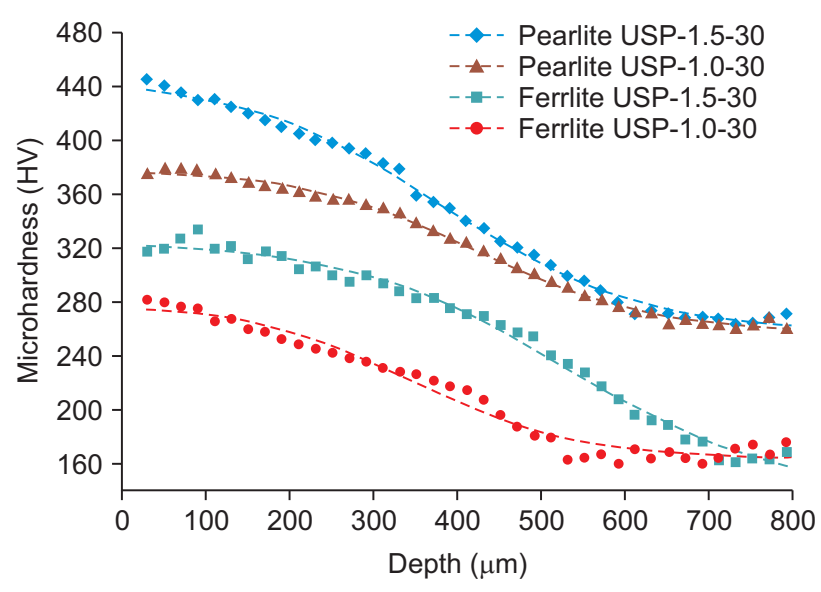

Fig. 1. Microhardness depth profile of ferrite and pearlite with ball size. USP, ultrasonic shot peening. 
face into the matrix up to $\sim 800 \mu \mathrm{m}$ of depth. The hardness of ferrite and pearlite increased by the USP treatment with higher hardness at longer peening time (Fig. 1). After $30 \mathrm{~min}$ USP treatment with $1.0 \mathrm{~mm}$ ball size, the hardness of ferrite and pearlite increased from $170 \mathrm{HV}$ and 260 to $275 \mathrm{HV}$ (61.8\% up) and $380 \mathrm{HV}$ (46.2\% up), respectively. After 30 min of USP treatment with $1.5 \mathrm{~mm}$ ball size, the hardness of ferrite and pearlite increased from $170 \mathrm{HV}$ and 260 to $320 \mathrm{HV}$ (88.2\% up) and $440 \mathrm{HV}$ (69.2\% up), respectively.

\section{SEM Analysis}

As shown in the SEM micrographs (Fig. 2), the number and size of graphite in the surface decreased by the USP treatment. The effect of USP treatment time, ball size, and graphite area fraction was quantified by analyzing the SEM micrographs with Image-Pro Plus software (Fig. 3).

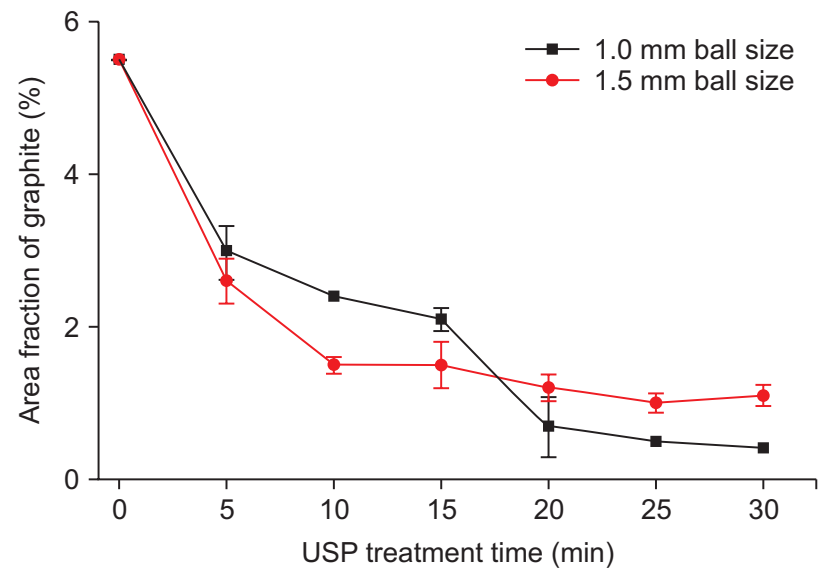

Fig. 3. Graphite area fraction of 500-7 near surface. USP, ultrasonic shot peening.
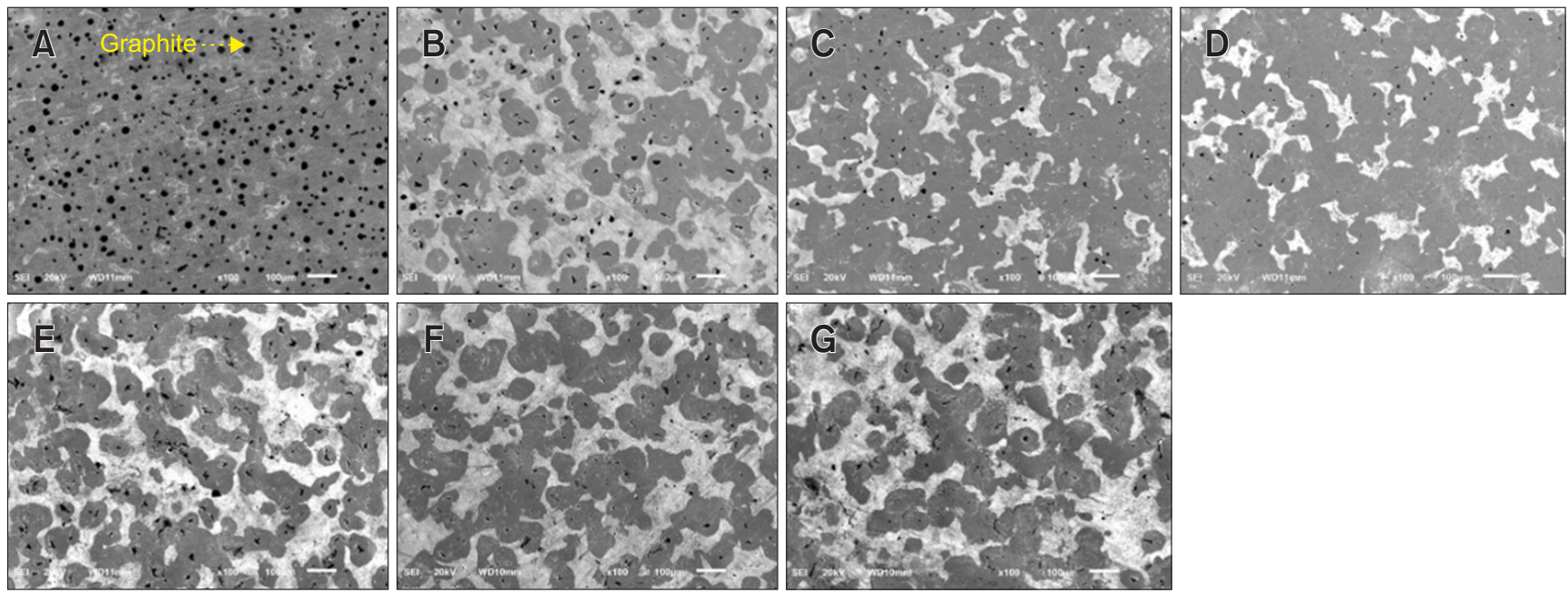

Fig. 2. Surface SEM micrographs. (A) Before; ball size $1.0 \mathrm{~mm}$, (B) Ultrasonic shot peening (USP) 10, (C) USP 20, (D) USP 30; ball size 1.5 mm, (E) USP 10, (F) USP 20, (G) USP 30.

A

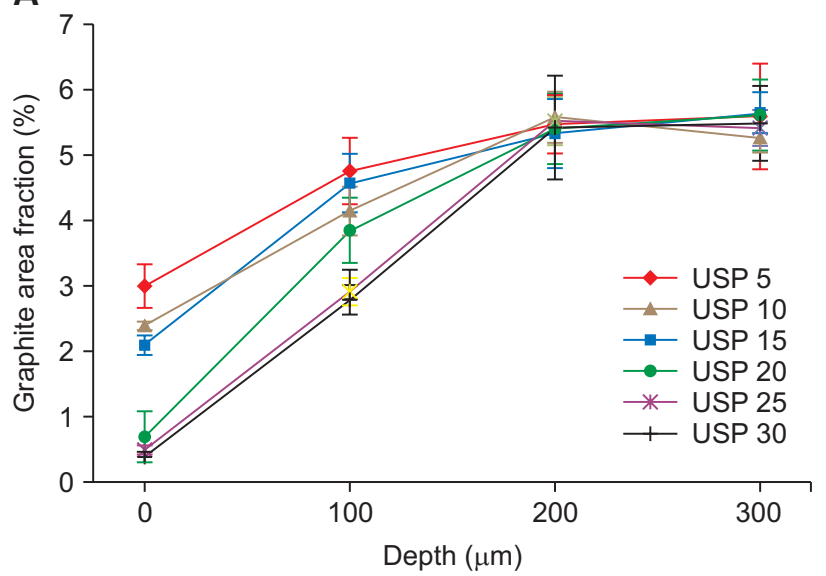

B

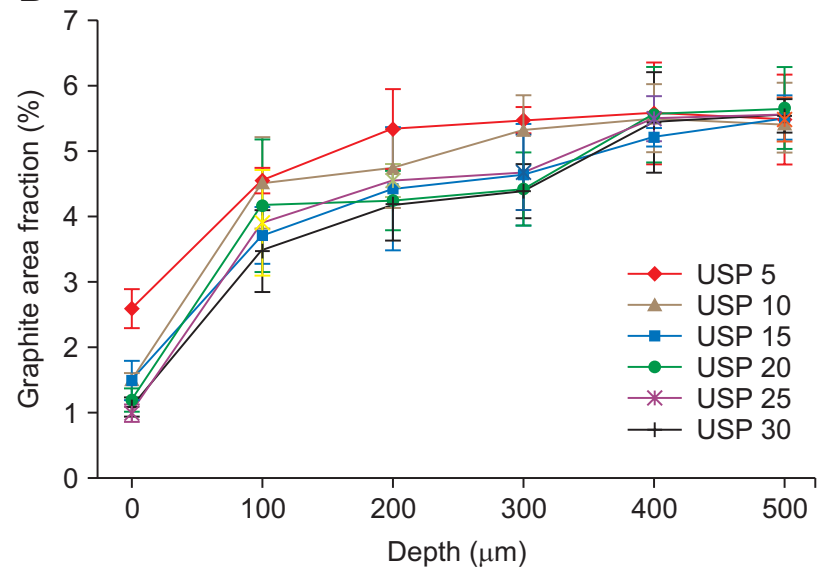

Fig. 4. Cross-sectional graphite area fraction with shot peening time and ball size. (A) $1.0 \mathrm{~mm}$, (B) $1.5 \mathrm{~mm}$. USP, ultrasonic shot peening. 
As shown in Fig. 3, after 30 min of the USP treatment, the area fraction of graphite measured on the specimens' surface decreased from $5.5 \%$ to $0.4 \%$ (treated with $1.0 \mathrm{~mm}$ ball size) and from $5.5 \%$ to $1.1 \%$ (treated with $1.5 \mathrm{~mm}$ ball size). From the SEM analyses of cross-section and specific depth plan view, the area fraction of graphite is found to decrease in the surface layer by the USP treatment. As the treatment time increases, the area fraction of graphite at the same depth decreases more (Fig. 4). Some breakage and exposure/connection of the soft and fragile graphite to the shot peening surface was observed. It has yet to be investigated and out of the scope of this works, if there is additional source of graphite fraction reduction upon shot peening.

After USP with $1.0 \mathrm{~mm}$ balls for 30 min treatment, the area fraction of graphite decreased from surface to $\sim 100 \mu \mathrm{m}$ depth. After the treatment with $1.5 \mathrm{~mm}$ balls for $30 \mathrm{~min}$, the area fraction of graphite decreased from surface to $\sim 300 \mu \mathrm{m}$ down. At shorter than 20 min of USP treatment, the large balls were more effective than the smaller balls at decreasing the area fraction of graphite. However, with $20 \mathrm{~min}$ and longer treatment, the smaller balls were more effective.

Compared to the specimens USP treated with the larger balls $(1.5 \mathrm{~mm})$, the small ball $(1.0 \mathrm{~mm})$ treated specimens showed a more smooth surface and more reduced graphite area frac-
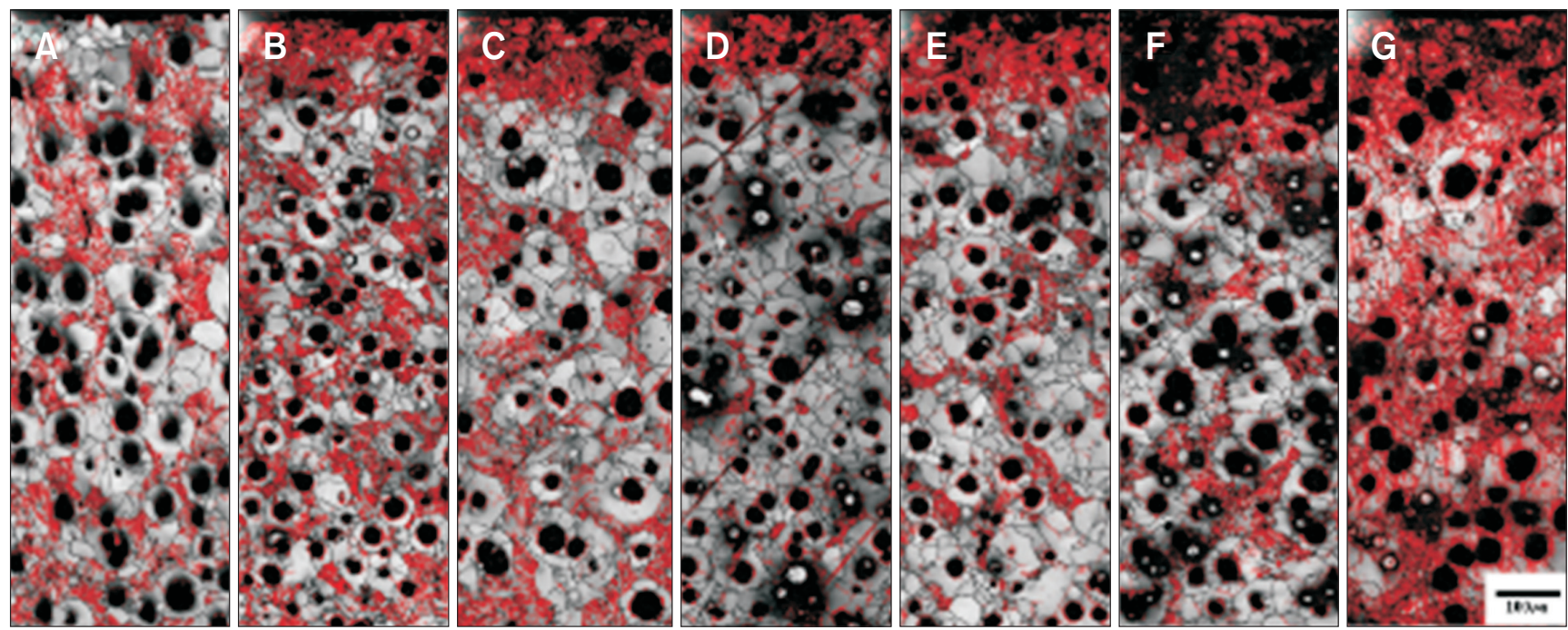

Fig. 5. Cross-sectional EBSD analysis. (A) Before, (B) ultrasonic shot peening (USP) -1.0-5, (C) USP-1.0-10, (D) USP-1.0-15, (E) USP-1.0-20, (F) USP-1.0-25, (G) USP-1.0-30.
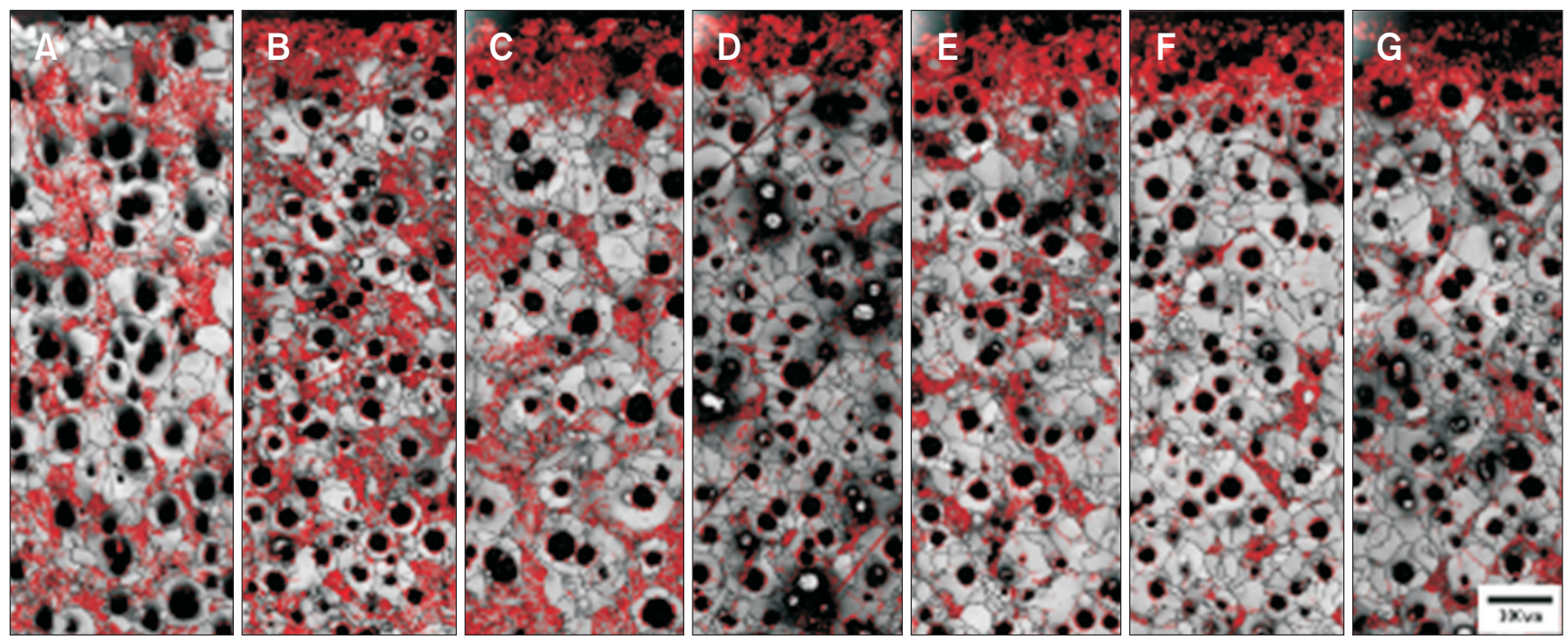

Fig. 6. Cross-sectional EBSD analysis. (A) Before, (B) ultrasonic shot peening (USP) -1.5-5, (C) USP-1.5-10, (D) USP-1.5-15, (E) USP-1.5-20, (F) USP-1.5-25, (G) USP-1.5-30. 


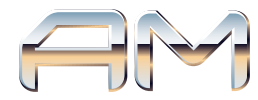

tion.

In cast iron, the wear resistance can be improved via spheroidization of graphite (Okabayasi et al., 1958) in addition the high damping of vibration (Luo et al., 2000). However, graphites may also act as the crack initiation sites (Berto et al., 2017; Khameneh et al., 2018), especially those on the surface (Ochi et al., 2001). Reduction of the graphite size and number density in the surface layer are believed to reduce crack initiation and propagation resulting in the extension of the fatigue life of the parts.

\section{EBSD Analysis}

In this work, the cross-sectional specimens were analyzed with EBSD for the grain size variation along the depth after
USP treatment. The subgrain size near USP treated surface decreased with the increase of the treatment time (Fig. 5 and 6). Fig. 7 shows the grain size variation along specific depth of cross-sectional specimens after the USP treatment with different time and ball size. With the ball size of $1.0 \mathrm{~mm}$, the average grain size near the surface decreased from $\sim 20$ to $\sim 7 \mu \mathrm{m}$ with 30 min USP treatment and the effect of the treatment was observed up to $\sim 300 \mu \mathrm{m}$ in depth. With the ball size of $1.5 \mathrm{~mm}$, the grain size near the surface decreased from $\sim 20$ to $\sim 10 \mu \mathrm{m}$, where $30 \mathrm{~min}$ USP treatment and grain size reduction was observed to the depth of $\sim 475 \mu \mathrm{m}$.

The larger balls resulted in an increased deformation depth. However, the peening of prolonged time with smaller balls induced more homogenous and refined grains in the deforma-
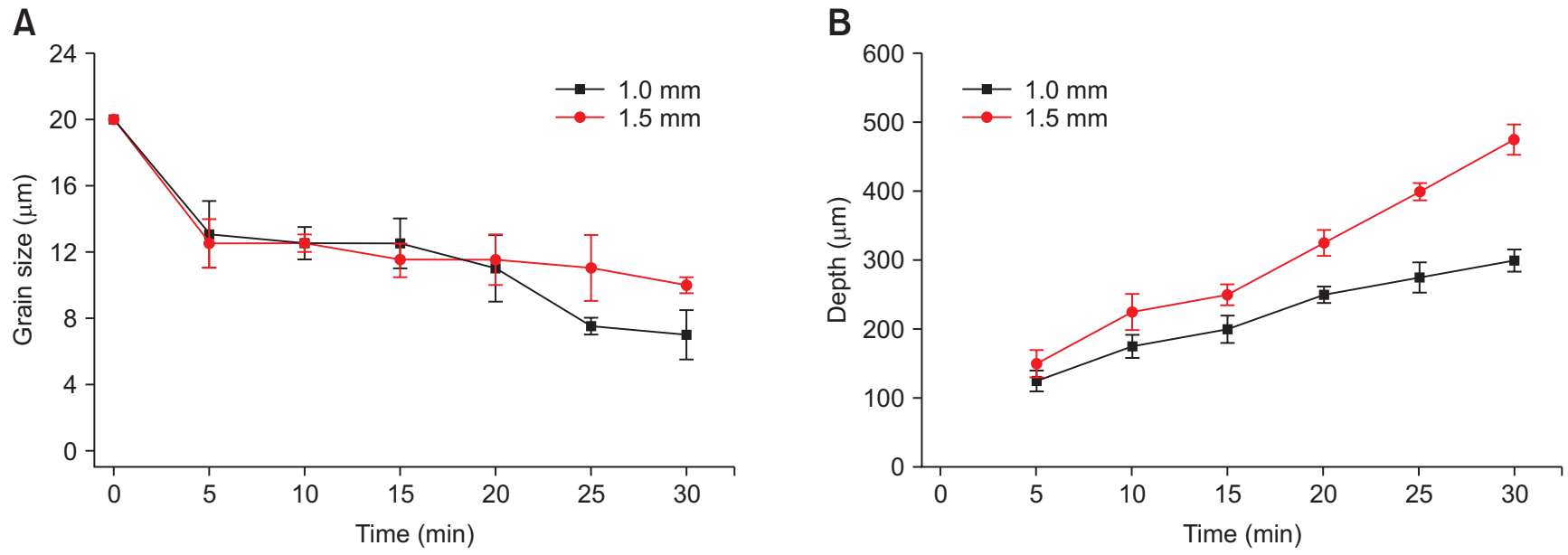

Fig. 7. (A) Grain size in surface and (B) in a specific depth with ultrasonic shot peening treatment time and ball size.
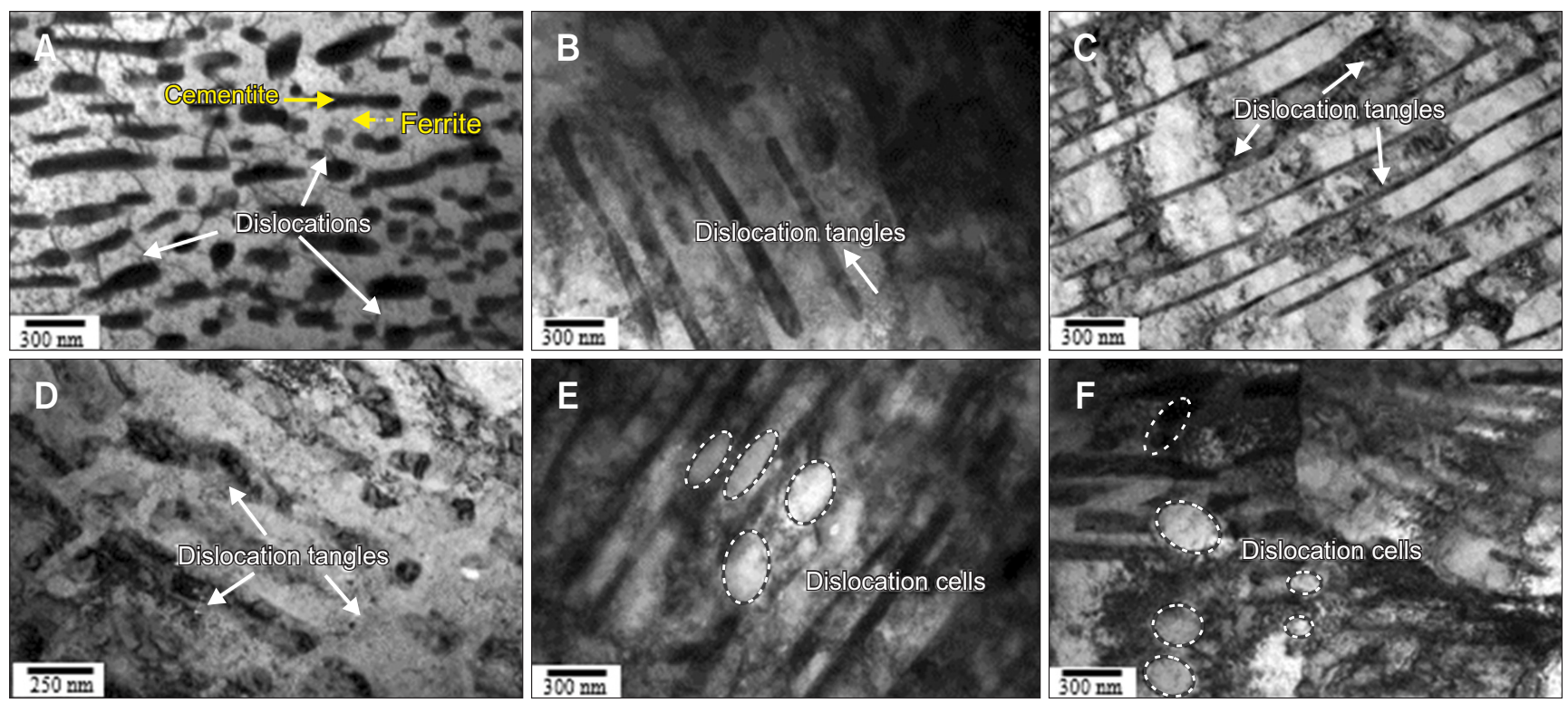

Fig. 8. Surface TEM analysis. (A) Before ultrasonic shot peening (USP), USP-1.5, (B) $5 \mathrm{~min}$, (C) $10 \mathrm{~min}$, (D) $15 \mathrm{~min}$, (E) $20 \mathrm{~min}$, (F) $25 \mathrm{~min}$. 
tion layer. In terms of grain refinement, larger balls are better for faster refinement with deeper effective depth. On the other hand, peening with smaller balls results in smaller grains when peened long enough.

\section{TEM Analysis}

After USP treatment, TEM analysis of the microstructural evolution of pearlite and ferrite on the surface region with depth specific observation was carried out. Before shot peening, there are few dislocations (DLs) in ferrite matrix (Fig. 8A). When shot peened for $5 \mathrm{~min}$ (Fig. 8B), $10 \mathrm{~min}$ (Fig. 8C), and 15 min (Fig. 8D) of USP treatment with $1.5 \mathrm{~mm}$ balls, dislocation tangles (DTs) in ferrite were formed and the cementites were fractured and displaced (Fig. 9A-C). After 30 min treatment, lamellar structure of the pearlite were completely destroyed (Fig. 9D). Some dislocation cells began to form after USP treatment (Fig. 8E and F) as reported in earlier study (Fang et al., 2014). After 30 min treatment, a number of nanoparticles were also formed at the surface layer (Fig. 10), in agreement with earlier reports (Bang et al., 2015; Pan et al., 2017; Wang et al., 2010).

After 30 min USP treatment, a lot of nanoparticles were


Fig. 9. Surface TEM analysis. Ultrasonic shot peening (USP)-1.5 (A) $15 \mathrm{~min}$, (B) 20 min, (C) $25 \mathrm{~min}$, (D) $30 \mathrm{~min}$.
Fig. 10. Surface TEM analysis. Ultrasonic shot peening (USP)-1.5 (A) 30 min BF, (B) 30 min DF, (C) 30 min BF, (D) 30 min DF. The circled spots in the insets are for the respective DF. 

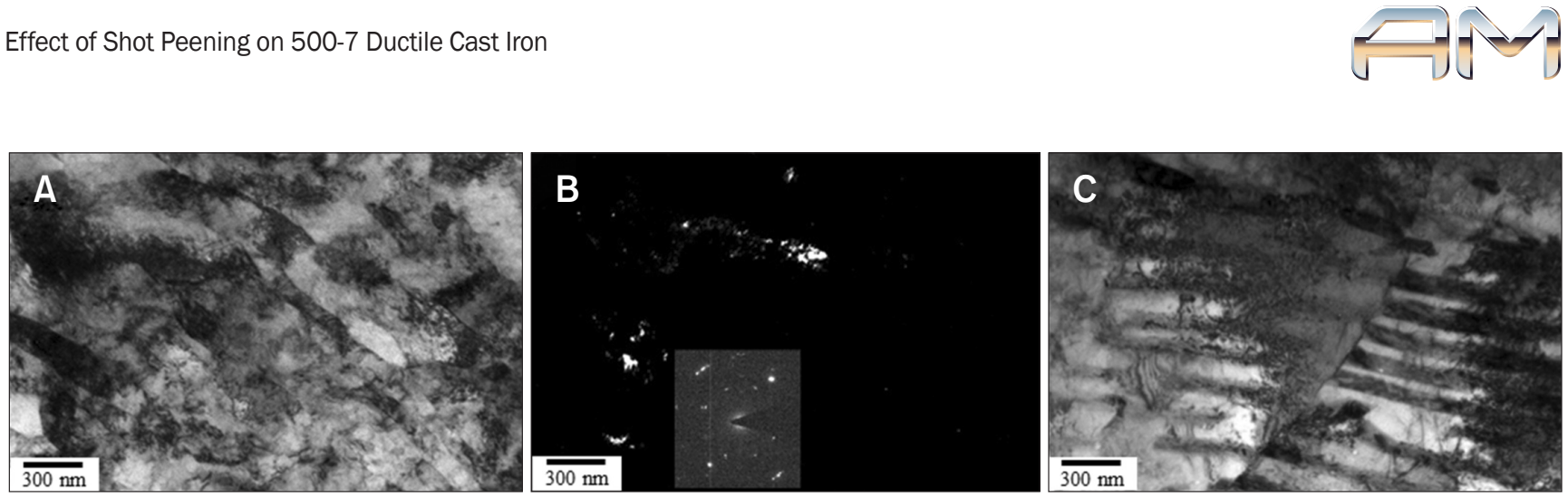

Fig. 11. Specific depth TEM analysis. Ultrasonic shot peening (USP)-1.5-30 min (A) BF, (B) DF, and $200 \mu \mathrm{m}$ deep (C) BF.

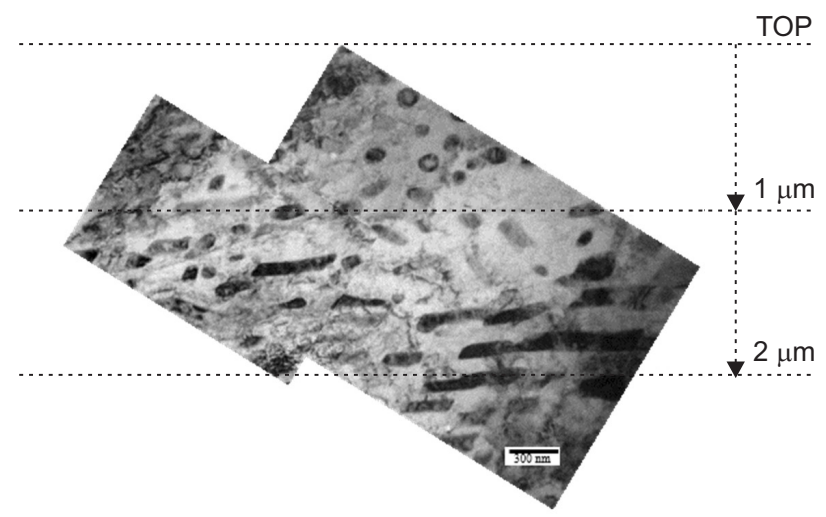

Fig. 12. Cross-sectional TEM analysis. Ultrasonic shot peening (USP)-1.5$30 \mathrm{~min}$.

formed mostly at the top layer (Fig. 10A and B). At the depth of $\sim 100 \mu \mathrm{m}$, few nanocrystallines were observed (Fig. 11A and B). At the depth of $\sim 200 \mu \mathrm{m}$, the pearlite maintained its original appearance (cementite and ferrite in lamellar distribution), similar to that shown in Fig. 11C.

The cross-sectional TEM observation revealed that the cementites in pearlite, especially at the top layer, were completely broken and displaced with reduction in the area fraction, which gradually recovered to its pre-peening lamella state as the depth increased, as shown in the cross-sectional micrograph (Fig. 12). The plastic deformation caused by USP treatment is gradually decreased with increasing depth.

The grain refinement procedure with progression of the USP treatment can be summarized into the following four steps, which is in good agreement with earlier report (Teshima et al., 2017):

I: Plastic deformation upon shot peening builds up dislocations to high density (DLs) leading to dislocation tangles (DTs) inside of ferrite, whereas cementites are fractured and dislocated. II: Dislocation tangles transform into dense dislocation walls (DDWs) and dislocation cells.

III: With further USP treatment, dense dislocation walls and dislocation cells transform to low-angles boundaries (LABs) and then to high-angles boundaries (HABs).

IV: As the USP treatment proceeds, ferrite grains repeatedly undergo the above-mentioned three processes, until ferrite grains finally reach the stable minimum size and form nanocrystalline grains.

The observation up to this point indicates that the shot peening of 500-7 ductile cast iron, a two phase alloy of hard cementite and soft and ductile ferrite breaks, separates and displaces the cementite as shot peening time increases. On the other hand, ferrite around cementite deforms with gradual dislocation density increase forming dislocation dense wall, subgrain boundary and then high grain boundary with no void/cavity, resulting in the grain refinement. The cracking of the cementite is due to its hard and fragile nature. On the other hand, the ferrite deformation behavior is characteristics of deformation of phases with high stacking fault energy (SFE) such as ferrite upon shot peening. Alloys of low SFE energy such as stainless steel, twins are preferred to dislocation formation and build up (He et al., 2015).

\section{SUMMARY}

In this study, microstructural evolution of 500-7 ductile cast iron of ferrite and perlite upon USP treatment is investigated in terms of the effect of USP ball size and treatment time. The following is summary of the findings:

1) After USP treatment, the hardness of ferrite and pearlite increased with the treatment time and ball size. In terms of hardness improvement, increasing the USP ball size is much more effective than increasing the USP treatment time.

2) In terms of reducing the number of graphite nodule, the bigger ball is more effective for shorter treatment time, while the smaller ball is more effective for longer treatment time.

3) Grain refinement occurred upon USP treatment. The larger balls resulted in an increased deformation depth. However, the peening with smaller balls induced more homogenously refined grains in the deformation layer.

4) Grain refinement occurs with USP treatment. The grain refinement during USP treatment could be divided into four steps. 5) The shot peening of two phase alloy of hard cementite and soft and ductile ferrite, 500-7, revealed the possibility of unique microstructure of high density second phase (cement- 
ite) surrounded by small grain size ferrite in the surface layer with low fraction of graphite.

\section{CONFLICT OF INTEREST}

No potential conflict of interest relevant to this article was reported.

\section{ACKNOWLEDGMENTS}

This work was supported by the National Research Foundation of Korea (NRF) grant funded by the Korea government (MSIP) (No. 2011-0030058).

\section{REFERENCES}

Bang C W, Seol J B, Yang Y S, and Park C G (2015) Atomically resolved cementite dissolution governed by the strain state in pearlite steel wires. Scr. Mater. 108, 151-155.

Berto F, Ferro P, and Salavati H (2017) Fatigue strength of sharp Vnotched specimens made of ductile cast iron. Eng. Fail. Anal. $\mathbf{8 2}$, 308-314.

Fang F, Zhao Y, Liu P, Zhou L, Hu X J, Zhou X, and Xie Z H (2014) Deformation of cementite in cold drawn pearlitic steel wire. Mater. Sci. Eng. 608, 11-15.

Ganapathy T and Bhoopathy T (2015) Experimental investigation of the residual stress and calculate average fatigue life and improved resistance to stress corrosion cracking on aluminum alloy 7075-T6 plates by using various shots through shot peening process. Int. J. Mod. Eng. Res. 5, 9-14.

He Y, Li K, Cho I S, Lee C S, Park I G, Song J I, and Shin K (2015) Microstructural characterization of SS304 upon various shot peening treatments. Appl. Microsc. 45, 155-169.

Khameneh M J and Azadi M (2018) Evaluation of high-cycle bending fatigue and fracture behaviors in EN-GJS700-2 ductile cast iron of crankshafts. Eng. Fail. Anal. 85, 189-200.

Kumar H, Singh S, and Kumar P (2013) Modified shot peening process. Int. J. Eng. Sci. Emerg. Technol. 5, 12-19.

Luo X and Chung D (2000) Vibration damping using flexible graphite. Carbon 38, 1499-1524.

Marsh K J (1993) Shot Peening: Techniques and Applications (EMAS, Warley).

Nam K, He Y, and Shin K (2018) Microstructural evolution of Super304H upon ultrasonic shot peening and subsequent annealing. J. Nanosci. Nanotechnol. 18, 6274-6277.

Ochi Y, Masaki K, Matsumura T, and Sekino T (2001) Effect of shot-peen- ing treatment on high cycle fatigue property of ductile cast iron. Int. J. Fatigue 23, 441-448.

Okabayasi K, Saito S, and Nakamura F (1958) Wear resistance of spheroidal graphite cast iron: effect of the amount of ferrite in the matrix on wear resistance. Japan Foundarymen's Soc. 30, 866-873.

Pan R, Ren R, Chen C, and Zhao X (2017) Formation of nanocrystalline structure in pearlitic steels by dry sliding wear. Mater. Charact. 132 , 397-404.

Radzikowska J M (2004) Metallography and microstructures of cast iron. Metallogr. Microstructur. 9, 565-587.

Shukla P, Swanson P, and Page C (2013) Laser shock peening and mechanical shot peening processes applicable for the surface treatment of technical grade ceramics: a review. Proc. MechE Part B: J. Eng. Manuf. 228, 639-652.

Teshima T, Kosaka M, Ushioda K, Koga N, and Nakada N (2017) Local cementite cracking induced by heterogeneous plastic deformation in lamellar pearlite. Mater. Sci. Eng.: A 679, 223-229.

Wang Y, Fang F, Wang L, Jiang J Q, and Yang H (2010) Microstructure evolution of cementite in cold drawn pearlitic steel wires. Trans. Mater. Heat Treat. 5, 022.

Watanabe Y, Hattori K, Handa M, Hasegawa N, Tokaji K, Ikeda M, and Duchazeaubeneix J M (2002) Effect of ultrasonic shot peening on fatigue strength of high strength steel. In: 10th International Conference on Shot Peening (ICSP10). pp. 305-310, (Electronics Inc., Tokyo).

William G (1992) Materials for Tribology (Elsevier, Netherland).

Yu H, Dong J, Yoo D, and Shin K (2009) Microstructural characterization of SS304 upon various shot peening treatments. J. Korean Phys. Soc. 54, 1161-1166 